\title{
OS RITOS EMPRESARIAIS NA RELAÇÃO COM COMUNIDADES RURAIS DA AMAZÔNIA MARANHENSE
}

\author{
Raifran Abidimar de Castro* \\ Edna Castro * *
}

\begin{abstract}
Neste artigo são apresentadas duas formas de atuação de representantes de grandes corporações junto a comunidades do interior do estado do Maranhão, na região Nordeste do Brasil, com o objetivo de demonstrar, através do conceito de ritos empresariais, como eles são desenvolvidos de maneira estratégica pelas grandes empresas, na sua relação com comunidades rurais. A abordagem metodológica adotada é a qualitativa, com ênfase em análises descritivas e explicativas. Foram utilizadas entrevistas semiestruturadas com representantes tanto das comunidades quanto das empresas, além de análises de documentos oficiais disponíveis ao público e de documentos internos disponibilizados para esta pesquisa. Como principal contribuição, tem-se que as grandes empresas desenvolvem a capacidade de interferir diretamente na sua avaliação pelos comunitários, a partir do momento em que selecionam os representantes que tenham vivências relacionadas com causas defendidas por seus antagonistas, nesse caso, os movimentos sociais do meio rural; ou ainda quando conseguem transformar os investimentos financeiros em referenciais positivos de atuação nas comunidades.

Palavras-chave: Porta-voz autorizado. Autoridade-autorizada. Representação. Capital simbólico. Inculcação.
\end{abstract}

\section{INTRODUÇÃO}

Considerando-se que as grandes empresas sempre enviam representantes para realizar trabalhos de reconhecimento nas comunidades em que suas atividades podem causar impactos socioambientais, as formas como esses representantes atuam têm grande potencial para produzir resultados positivos, caso eles tenham a capacidade de dialogar e de antecipar problemas locais. Tais ganhos dependem dos procedimentos adotados tanto pela empresa quanto pelo profissional selecionado.

Nesse contexto, o objetivo deste artigo é apresentar como os ritos empresariais são desenvolvidos de maneira estratégica pelas grandes empresas, na sua relação com comunidades rurais. Para tanto, são apresentadas duas formas de atuação de representantes de grandes corporações junto a duas comunidades do interior do estado do Maranhão, região Nordeste do Brasil.

* Instituto Federal do Maranhão (IFMA).

Avenida Projetada, s/n, Vila Progresso. Cep: 65.930-000. Açailândia - Maranhão - Brasil. raifrancastro@ifma.edu.br

${ }^{* *}$ Universidade Federal do Pará. Instituto de Filosofia e Ciências Humanas.

Rua Augusto Correa, 1. Guamá. Cep: 66.075-750. Belém - Pará

- Brasil. edna.mrcastro@gmail.com
Para ampliar a liberdade de exposição dos dados, informações e avaliações sobre os dois casos, os nomes das empresas (aqui denominadas de Empresa 01 e Empresa 02) e de seus respectivos representantes (aqui denominados de Representante Empresa 01 - RE01 e Representante Empresa 02 - RE02) não são mencionados. Optou-se por esse procedimento, pois o valor maior deste artigo se encontra na descrição detalhada dos ritos e dos usos que os representantes fazem do arcabouço político, financeiro e simbólico que recebem primeiramente das empresas e, em seguida, das comunidades.

Destacam-se, no processo metodológico, a riqueza e o detalhamento dos resultados da análise empírica aqui apresentada. Foram utilizadas entrevistas semiestruturadas (Boni; Quaresma, 2005; Duarte, 2004) com representantes das empresas, das duas comunidades e dos órgãos públicos que nelas atuam. Os dados foram complementados com análises de documentos oficiais disponíveis ao público, além de documentos internos disponibilizados para esta pesquisa. A abordagem metodológica adotada foi a qualitativa, com ênfase em análises descritivas e explicativas (Godoy, 1995; Neves, 1996). 
A primeira parte do artigo apresenta uma fundamentação teórica sobre a atuação de grandes empresas junto a comunidades rurais, complementada com as ideias centrais deste artigo aplicadas à análise desse tipo de relação. Em seguida, são apresentadas as características básicas de cada agente estudado (empresas e comunidades), bem como informações importantes sobre os setores de cada empresa dedicados à relação com comunidades. Por fim, são descritas as principais estratégias adotadas pelas corporações e por seus interlocutores, especificando-se como seu desenvolvimento nos ritos empresariais tem resultado em novas representações empresariais, repercutindo diretamente no cotidiano comunitário.

\section{A AÇÃO ESTRATÉGICA EMPRESA- RIAL E A MUDANÇA NOS RITOS}

Os grandes investimentos na indústria, bem como nos seus aparatos logísticos de apoio, tornarem-se destaque na região comumente chamada de Amazônia Maranhense, principalmente a partir do ano de 2010. O destaque para a instalação de indústrias nos municípios de Açailândia e Imperatriz não se deve apenas à propagação dos possíveis ganhos financeiros, mas também aos impactos స్ Socioambientais, pois tais empreendimentos 荌 estão ligados à mineração e à expansão de monoculturas florestais.

Além da problemática socioambiental que envolve esses tipos de atividades, também tem recebido destaque a forma como as empresas buscam se relacionar com as comunidades circunvizinhas, principalmente da área rural. Percebe-se que há um importante investimento empresarial na redução de possíveis relações conflituosas que resultem em perdas financeiras.

Embora a relação entre empresas e comunidades não seja nova, o que há de novo nesse contexto é a modificação das estratégias empresariais. Há autores como Marchiori e Oliveira (2009) que citam exemplos de como a ética tem pautado as ações corporativas, na medida em que elas buscam a legitimidade e a credibilidade de suas atuações. Já em outro extremo, Layrargues (1998) e Tenório (2006) destacam que existem discordâncias sobre esse entendimento, pois há diversos danos socioambientais impulsionados pela ação empresarial em diversos tipos de comunidades.

Problemas como a poluição (sonora, do ar, da água e do solo), acidentes com maquinário e reassentamentos involuntários enquadram-se entre os danos socioambientais com maior influência no cotidiano comunitário. Ainda assim, as empresas buscam estabelecer, segundo seus modos de avaliação, uma relação pautada na aplicação de estratégias que possibilitem uma avaliação positiva, buscando a confiança comunitária. Nesse sentido, Burkle (1999) destaca que uma relação de vizinhança confiável pode ser estabelecida com base nas seguintes estratégias: ampliar o relacionamento com as comunidades; identificar e monitorar os anseios e preocupações das comunidades que podem impactar a empresa; e planejar ações que estejam vinculadas às necessidades empresariais. O autor cita ainda que uma "relação sustentável” (Burkle, 1999, p. 102, tradução nossa), pode ser estabelecida com o fortalecimento de uma imagem íntegra de empresa no seio da comunidade.

Planejar e agir estrategicamente têm sido as ferramentas empresariais e, obviamente, isso não é algo novo. Mas é importante considerar que, apesar de as manifestações dos movimentos sociais contra grandes empreendimentos ainda existirem, elas vêm passando por um processo de redução. Nesse sentido, entender os fatores que interferem diretamente nesse processo é de extrema importância, considerando-se, principalmente, casos que que ele possa ser cuidadosamente analisado. Com isso, "[...] um dos passos a ser analisado é, justamente, como o sistema de interação é estabelecido e que regras são postas como parte do processo de negociação dos interesses considerados como válidos para o debate” (Ferreira, 2011, p. 72). 
Para Vieira (2010), a cultura organizacional e a ação empresarial consideram o contexto cultural em que se inserem para agir estrategicamente. Para Freitas (1997), as grandes empresas têm grande capacidade de perceber as mudanças sociais e de responder a elas. Estas “[...] respondem não apenas de maneira operacional, funcional, mas também de maneira simbólica, através de sua cultura organizacional e do repasse de todo um imaginário" (Vieira, 2010, p. 70). Verifica-se, portanto, que o processo de comunicação empresarial voltado para comunidades tem regras rigidamente estabelecidas para a concretização das estratégias corporativas, utilizando-se principalmente dos processos de comunicação com esses grupos.

Ao tratar das estratégias de comunicação, Almeida e Nunes (2007) salientam que elas só obterão resultados positivos se forem ratificadas pelos agentes (altos escalões). Já Kunsch (2003) destaca ainda a necessidade de que essas ações considerem não apenas os objetivos da organização, mas também os de seus interlocutores. Há, assim, dois importantes pontos a serem contemplados: ao se relacionarem com comunidades, a partir de um pilar estratégico, devem ser considerados os interesses empresariais; outro fator que surge é a necessidade de buscar transmitir uma percepção de acolhida e de atendimento das demandas comunitárias.

As duas situações citadas, apesar de paradoxais devem ser analisadas. Nesse ponto, destaca-se a importância dos interlocutores dessa relação, surgindo, então, o agente de intermediação, que é estrategicamente selecionado pelas empresas. Importa considerar ainda que as regras e os procedimentos de relação são estabelecidos pelos superiores, que visam a atender aos interesses de seus investidores: "Os profissionais de comunicação organizacional e relações públicas desenvolvem papel estratégico, ao administrar esses relacionamentos, em busca da conciliação dos interesses das organizações e também de seus públicos" (Andrade, 2010, p. 103).

Esses agentes, ainda que influenciados pela instituição, seguem padrões racionais de ação, nos quais se conjugam as demandas da empresa e as suas próprias, como pessoas (Selznick, 1972). Apesar de uma contextualização complexa, é importante considerar que, acima de tudo, há uma importante influência da organização nas ações de seus representantes, pois, além de acompanhar as ações das comunidades, os altos executivos também avaliam seus agentes.

Ainda sobre esses representantes, França e Freitas (1997) ressaltam que há os profissionais encarregados de estabelecer uma relação harmoniosa entre as corporações e seus públicos de interesse, buscando apoio da opinião pública para seus negócios. Para Fernandes (2010), a pessoa que recebe esses investimentos empresariais tem como uma das principais funções a redução da ocorrência de conflitos, pois devem agir prevendo-os, informando-os às instâncias superiores, e até exterminando qualquer possibilidade de ocorrência (França; Freitas, 1997).

Ao tratar da questão da delegação e da pessoa que a recebe, Bourdieu (1989, p. 12) a relaciona com o poder simbólico que ela exerce sobre os que são seu foco, pois “[...] o poder simbólico é, com efeito, esse poder invisível o qual só pode ser exercido com a cumplicidade daqueles que não querem saber que lhe estão sujeitos ou mesmo que o exercem”. Sobre esse fator, Almeida (1997, p. 28) destaca que os "atos de autoridade autorizada" colaboram para que os processos de magia social sejam utilizados, através dos mecanismos de investidura, como "fazer-se conhecer" e "fazer-se reconhecer", para que os limites arbitrários sejam considerados legítimos. Inclusive, "Os atos de autoridade ou atos autorizados são mecanismos utilizados por uma instituição ou por um grupo de indivíduos para que sejam representados por outro" (Bourdieu, 1991c, p. 114).

Neste sentido, Hardy e Clegg (1996) destacam que as atividades atuais de disciplinamento direcionadas aos representantes empresariais vão para além da dependência financei- 
ra ou do estabelecimento de obrigações contratuais, pois se tem utilizado de estratégias mais complexas de poder, como a simbologia positiva de empresa socialmente justa e responsável. Como destaca Bourdieu (1991a), busca-se um poder para além das estruturas físicas e impostas, passando-se par o nível dos sistemas simbólicos. Relacionando-se com a temática deste artigo, constata-se a expectativa de que, nos altos escalões corporativos, essa simbologia positiva seja disseminada no cotidiano das comunidades, tornando-se ainda um trabalho político de representação.

Este trabalho político faz com que os indivíduos que recebem os investimentos para defender os objetivos de uma coletividade se percebam como importantes atores para o grupo que representam. Para isso, são utilizadas cerimônias e manifestações públicas de que tal agente recebeu esse poder do grupo (Bourdieu, 1991b). Deve-se considerar ainda que a ação de representação só pode ser exercida por pessoas que estejam verdadeiramente engajadas com as causas do coletivo que se propõem a representar, "[...] fazendo-o falar por sua boca e representando-o com seu corpo, convertido em símbolo e emblema mobilizador" (Bourdieu, 2001, p. 53). Tem-se, assim, que se deve considerar como os representantes das corporações se utilizam dos símbolos em suas estratégias.

Ao tratar dos símbolos, Hofstede (1991) também destaca que eles são de grande significância para a representação de grupos e para a manifestação da autoridade dos representados. Já para Enriquez (1992), eles ainda ampliam a capacidade de estruturação da "cultura de empresa”. Silva (2000) complementa que os símbolos são utilizados para a expressão de identidades, na medida em demonstram ou tentam mascarar os valores aceitos e disseminados internamente. É importante considerar ainda que eles são importantes para o estabelecimento de ritos, na medida em que se tornam referenciais práticos a serem disseminados e seguidos. Para isso, são considerados os agentes, os recursos e as ações, amparados pelos referenciais simbólicos empregados.

Sobre as organizações, Srour (1998) afirma que elas combinam agentes sociais e recursos que se convertem em instrumentos estratégicos para a ação. Considera-se também o que Aktouf (1993) coloca como "cultura organizacional”, quando ele a define como um emaranhado de conhecimentos e evidências disseminado pelos componentes da organização, na busca pela ampliação do conhecimento local. Conjugadas, tais ações visam a ampliar a capacidade de as empresas potencializarem seu capital simbólico positivo, mesmo que seja através da cooptação (Bourdieu, 2001).

Como destaca Castells (1999), há ainda uma luta pela manipulação dos símbolos, na qual se valorizam novas representações que influenciam as formulações da realidade realizadas pelos indivíduos. São diversas as estratégias utilizadas para essa manipulação, mas, em termos de análise sociológica, obtêm destaque a cooptação e a inculcação. Sobre a cooptação, Bourdieu (2001, p. 85) salienta que se trata de "[...] operações nas quais se presta atenção aos sinais de competência e ainda mais aos indícios quase imperceptíveis, quase sempre corporais, postura, compostura, maneiras, disposições de ser [...]". Para Rosa e Brito (2009), as organizações se utilizam de estratégias de inculcação e de trabalho pedagógico para fazer com que os receptores de investimentos institucionais realizem suas ações de acordo com os objetivos pretendidos por elas. Para isso, as grandes corporações têm se utilizado de seus agentes a fim de ter acesso direto aos anseios comunitários, e, tendo esse 
conhecimento, obter maior êxito sobre na relação com tais comunidades, como foi dito, utilizando-se de uma carga simbólica que repasse uma nova representação empresarial. Nesse ponto, surge a importância do entendimento a respeito do "porta-voz autorizado" (Bourdieu, 1991c, p. 58).

Para Bourdieu (1991c, p. 58), esse tipo de representante só tem o poder de utilizar as palavras e, a partir delas, buscar fazer com que os outros ajam de acordo com seus objetivos, “[...] porque o seu discurso concentra em si o capital simbólico do grupo que tenha delegado a ele, e do qual é o mandatário”. Para esse autor, “[...] o porta-voz autorizado é aquele a quem cabe e sobre quem cabe falar em nome da coletividade. É ao mesmo tempo o seu privilégio e seu dever [...]" (Bourdieu, 1991b, p. 71).

Em termos de relações e do estabelecimento de novas representações, Kleba e Wendausen (2009) salientam que a escolha de estratégias dos agentes está relacionada à estrutura do poder que lhes é concedido. Com isso, ao se adaptarem às exigências da ação estratégica das empresas e ao obterem resultados positivos com essa ação, tais representantes recebem maior capacidade de poder dentro das organizações que representam (Cappelle; Melo; Brito, 2005). E, caso os ganhos sejam significativos, como destaca Laclau (1996, p. 22), “[...] o representante também está transformando a identidade do representado".

Portanto, ao agirem no cotidiano comunitário, os representantes das empresas buscam alterar a avaliação negativa que os comunitários têm das grandes corporações empresariais e ampliar seu poder dentro dessas organizações, na medida em que esses resultados sejam alcançados. Ou seja, não bastando os interesses empresariais, há, ainda, os interesses de seus representados. Por isso, é importante considerar tanto os ritos adotados pelas empresas quanto a aplicação realizada por seus representantes.

No sentido aqui empregado, os ritos são utilizados pelas pessoas que recebem o poder de representação de duas maneiras. Elas podem, primeiramente, utilizar essa investidura de representação para impor autoridade e respeito às suas ações e enunciados; ou também podem realizar ações e formular enunciados que se relacionem com os objetivos esperados a partir da representação para a qual foram investidas (Bourdieu, 1991d). Dentre os ritos organizacionais empresariais destacados por Trice e Beyer (1984), merecem destaque os de renovação e de reforço. Os primeiros se relacionam às ações da empresa voltadas para ampliar sua capacidade estrutural de ação estratégica; os de reforço visam a disseminar a força de ação e os benefícios que a empresa traz às partes interessadas.

Para entender como têm ocorrido essas modificações nas estratégias adotadas pelas grandes corporações e, consequentemente, por seus representantes na relação com comunidades, foram selecionados empiricamente dois casos que demonstram como empresas que historicamente enfrentam manifestações e (ou) processos judiciais realizados por comunidades aplicam formas de atuação que reduzem a possibilidade de conflitos socioambientais.

\section{OS AGENTES: as empresas e as comunidades}

Neste artigo, são analisados dois casos que representam as realidades locais: uma empresa ligada ao ramo da mineração e sua relação com a comunidade de um assentamento rural; e uma empresa do ramo de silvicultura com a comunidade de uma reserva extrativista. O histórico das empresas e das comunidades é diferente, encontrando-se apenas nos tradicionais mecanismos de atuação na sociedade. Nesse sentido, é importante descrever as principais características desses quatro agentes, ainda que as suas identidades permaneçam preservadas, como foi informado na metodologia.

A empresa ligada ao ramo da mineração (Empresa 01) atua no mercado há mais de 50 
anos. Ela enfrenta diversos problemas na relação com comunidades nas regióes onde atua, principalmente devido às atividades de extração, de transporte e de manipulação de seus produtos. Para reduzir os problemas ligados ao relacionamento com comunidades, tem se empenhado na elaboração de instrumentos técnicos e operacionais que reduzam ou eliminem a ocorrência desses problemas. Manuais e sistemas digitais têm sido utilizados para possibilitar maior acompanhamento das demandas e reduzir a ocorrência de manifestações contra a empresa. Nesse sentido, há um grande empenho na divulgação das ações avaliadas como positivas, tornando-se uma estratégia constante da equipe da mineradora, cujo principal objetivo é tentar demonstrar que a empresa se preocupa com os problemas atinentes aos danos socioambientais causados por suas atividades. Apesar disso, a ocorrência de conflitos nas obras de logística da empresa demonstra que há um paradoxo entre o divulgado e suas ações.

A empresa mantém profissionais diretamente ligados a seu quadro e também trabalhadores terceirizados para o estabelecimento do que é denominado por eles como diálogo com as comunidades circunvizinhas às suas atividades. Mas é importante destacar que os terceirizados fazem apenas trabalhos básicos de acompanhanento do processo, como visitas às comunidades จิ para coleta de informações. As reuniões onde há decisão sobre procedimentos e investimentos a serem adotados são acompanhadas pelos profissionais diretamente ligados à empresa.

A partir da avaliação do processo histórico de atuação da Empresa 01, verifica-se que, dentre os principais objetivos de sua ação junto às comunidades - todos eles pautados numa ação estratégica -, estão: aumentar o conhecimento do cotidiano comunitário; acompanhar processos que podem trazer riscos operacionais; ampliar a visibilidade positiva da empresa; e ampliar o atendimento das demandas, reduzindo possibilidades de conflitos.

Mesmo com essa grande quantidade de procedimentos e orientações, momentos de tensão ainda ocorrem na relação com as comunidades, como, por exemplo, no caso apresentado a seguir. Há um funcionário que é responsável direto pelo relacionamento com comunidades da região aqui analisada. Mas, ainda que tenha grande poder de decisão, ele deve seguir as orientações de coordenadores e diretores regionais ou estaduais. Cabe a esse representante empresarial local apenas conseguir maiores informações sobre os anseios e sobre os processos de organização das comunidades. Além disso, ele tem se apresentado como um orientador para as comunidades, na medida em que intermedeia os processos de financiamento na comunidade aqui analisada e nas demais da região. Frequentemente, ele é transferido para atividades em outras regióes do estado do Maranhão.

A empresa ligada ao ramo da silvicultura (Empresa 02) também atua no mercado há mais de 50 anos, mas apenas a partir da década de 1980 iniciou um processo de expansão em âmbito nacional e internacional. A atuação na região aqui considerada foi iniciada no ano de 2008, e sua produção, na Amazônia, visa, prioritariamente, a atender à demanda internacional.

Como se trata de uma empresa com décadas de atuação no seu principal ramo, já conhece os conflitos com comunidades, e sabe, principalmente, quais os mecanismos a serem adotados para reduzi-los. Ao analisar os relatórios de sustentabilidade da empresa, identifica-se que seus representantes, nesse caso os altos executivos, sabem que a estratégia que mais surte efeitos positivos é o uso de recursos financeiros aplicados em comunidades de baixo investimento público. Mas, acima de tudo, o diferencial dessa empresa, em relação à Empresa 01 , diz respeito à seleção e à atuação de seus representantes ${ }^{1}$. Eles são vinculados diretamente à empresa e, portanto, não há participação de empresas terceirizadas nesse setor, havendo um setor específico ligado à área socioambiental cuja finalidade é estabelecer o relacionamento com as comunidades da região.

${ }^{1}$ Esse processo é descrito detalhadamente no item posterior. 
Como foi mencionado, um dos focos deste artigo é a relação entre a Empresa 01 e uma comunidade de assentamento. O grupo de assentados, que hoje faz parte dessa comunidade (Comunidade 01), iniciou suas atividades no ano 2000, quando ainda eram poucas as ações públicas para assentamento de famílias na região. Depois de anos acampados às margens das rodovias locais, ocuparam a fazenda onde hoje se localiza a comunidade.

Como o assentamento ainda se encontra em fase de implantação, são poucos os trabalhadores que já têm algum retorno financeiro dos trabalhos com a terra, os quais têm sido pequenos por conta do pouco apoio das instituições públicas. Na maioria dos casos, os trabalhadores vivem do apoio dos governos estadual e federal, por meio de políticas de ampliação de renda (Bolsa Família), e de cestas básicas doadas pelo Instituto Nacional de Colonização e Reforma Agrária (INCRA). O plantio e a criação de animais estão em fase inicial, mas ainda sem nenhum tipo de financiamento.

O Contrato de Concessão de Uso (CCU) foi liberado pelo INCRA em 2013. Até o início de 2015, a comunidade dependia exclusivamente do poço artesiano que já existia no momento da ocupação, mas existiam problemas de abastecimento devido, principalmente, aos problemas com a manutenção da bomba hidráulica e do encanamento para a distribuição da água para a agrovila. Por conta dos poucos investimentos e também por ser um dos principais prejudicados pelas ações da mineradora, por conta da proximidade da agrovila das atividades logísticas da empresa, essa comunidade tem demonstrado ser um agente importante nas manifestações, seja contra as organizações estatais, seja contra as empresas. Além disso, trata-se de uma das comunidades que buscam ampliar as parcerias com sindicatos e outras organizações que apoiem os movimentos sociais do campo.

O outro caso analisado é o da relação entre a comunidade de uma Reserva Extrativista (RESEX), aqui denominada de Comunidade 02 com a silvicultora, Empresa 02. É importante destacar que, durante anos, as famílias que hoje estão na reserva tiveram de estabelecer lutas políticas para a devida ocupação e regularização da área como reserva. Mas há autores ${ }^{2}$ que consideram o estabelecimento dessa reserva apenas como estratégia dos comunitários para ocupação legal da área, sendo importante informar que houve conflitos judiciais e políticos entre os fazendeiros e políticos da região, de um lado, e os trabalhadores rurais, de outro.

Em 2003, foram realizados os processos de loteamento e de distribuição dos lotes entre os sócios da associação que representa a comunidade. Atualmente, há em torno de 150 famílias ligadas diretamente à RESEX, segundo dados fornecidos pelo Instituto Chico Mendes de Conservação da Biodiversidade (ICMBio). Devido à falta de apoio, ou à baixa capacidade dos comunitários para ampliar suas rendas, há relatos de que a maioria dos jovens sai da RESEX e busca outras oportunidades em municípios como Goiânia (GO) e Brasília (DF). Além disso, há um descontentamento com as organizações representantes da reserva, pois não se tem conseguido articular a comunidade para implantar projetos que melhorem a condição socioeconômica dos extrativistas, ainda que elas se empenhem em concretizar projetos socioambientais.

Um fator importante a ser considerado é a dificuldade de as duas comunidades concretizarem projetos de ampliação de renda em parceria com as organizações estatais. Verifica-se, assim, uma lacuna na atuação das duas empresas, e seus representantes têm tido a habilidade de usá-la para reduzir a possibilidade de conflitos com essas comunidades, e também, alterar a avaliação negativa das empresas, situação observada nos dois casos aqui analisados. São estratégias utilizadas pelos representantes, ou "porta-vozes autorizados", como classifica Bourdieu (1996c, p. 58).

${ }^{2}$ Esses autores não podem ser citados, para não se identificar a comunidade estudada. 


\section{OS PORTA-VOZES AUTORIZADOS E SEUS RITOS}

Como foi mencionado anteriormente, passamos a destacar as análises sobre as estratégias adotadas pelos representantes empresariais na relação com as comunidades. Mas importa destacar que tais estratégias têm como objetivos: a busca pelo apoio comunitário para as ações empresariais (França; Freitas, 1997); a redução da possibilidade de conflitos (Fernandes, 2010); a aplicação de estratégias orientadas pela empresa ou resultantes de suas avaliações (Selznick, 1972); e o uso dos símbolos na busca de influência diante de seus interlocutores (Bourdieu, 1989, 1991a, 1991b, 1991c, 1991d). Tais representantes se apresentam como "autoridades autorizadas" (Almeida, 1997, p. 28) e "porta-vozes autorizados" (Bourdieu, 1991b, p. 71).

Nos dois casos, as empresas são avaliadas nas regiões onde atuam segundo duas vertentes: na primeira, a dos políticos, dos pequenos empresários e de boa parte dos trabalhadores, são tidas como organizações que geram empregos e renda; já nas comunidades que têm vivência com movimentos sociais, há uma grande quantidade de pessoas que as avalia como degradadoras do meio ambiente e ^ estimuladoras de concentração de renda. Porऽे tanto, a ação dos representantes pauta-se na obrigatoriedade de que a avaliação negativa e a possibilidade de geração de conflitos diretos sejam contornadas. Como destaca Freitas (1997), as empresas percebem as problemáticas em que se envolvem e buscam alterá-las $\dot{2}$ \& ficar identidades negativas (Bueno, 2005). empresa. Nos ritos de seleção dos representantes para os campos aqui analisados, no caso do RE01, foram considerados alguns fatores. Os funcionários que passaram pelo campo antes dele não lograram êxito, pois a comunidade ampliou sua capacidade de pressão sobre a empresa, na medida em que passaram a realizar manifestações públicas, e conseguiram apoio de organizações locais, de movimentos sociais e do Ministério Público Federal (MPF). Por serem de empresas terceirizadas, a contratante não repassava poderes para eles, como registram os manuais da empresa, o que foi confirmado pelo RE01 durante as entrevistas. Assim, a empresa resolveu indicar alguém com experiência na área de comunicação com comunidades e na resolução de conflitos; além desses fatores, contou como ponto positivo o fato de que ele, por residir há vários anos na região, conhece os contextos sociopolíticos das comunidades locais.

Pelo fato de ser uma funcionária de carreira da empresa, ela recebeu maior apoio para dialogar e negociar acordos com os assentados. Ainda assim, afirma que precisou seguir os trâmites internos da Empresa 01, o que se tornou um fator complicador, pois isso burocratiza o atendimento às demandas comunitárias. Apesar das exigências das regras internas, o RE01 recebe maior apoio da representada. Com isso, a empresa estabeleceu melhor seus "atos de autoridade" (Bourdieu, 1991b, 1991c), na medida em que também consegue ser mais ágil no atendimento aos anseios dos assentados.

Antes das ações do RE01, a Empresa 01 enfrentou sérios problemas de conflito direto com a comunidade, e os assentados chegaram a realizar manifestações que foram destaque no noticiário nacional. Segundo esses assentados, eles não se sentiam respeitados pela empresa, que não atendia às suas demandas, destacando que os representantes da empresa não demonstravam capacidade de articulação e de diálogo, e só frequentavam a comunidade para obter informações sobre o cotidiano do assentamento. Não havia retorno sobre in- 
vestimentos sociais, um processo que resultou na manifestação e em um novo momento de relação com a chegada do RE01, que passou a frequentar a comunidade constantemente fazendo reuniões para "fazer-se conhecer" e "fazer-se reconhecer", como é destacado por Almeida (1997), e intentando construir uma nova representação da empresa como socialmente justa e responsável (Bourdieu, 1991b), com a busca de diálogo correto e de negociação de melhorias, como consta nas atas das reuniões realizadas com a comunidade. Apresentando-se como simpatizante dos movimentos sociais do campo, destaca os ganhos de outras comunidades que estabeleceram um diálogo "positivo" com a empresa, estando sempre fardado e expressando os sinais incorporados (Bourdieu, 1991d, p. 49), além de demonstrar capacidade de articulação para a implantação das demandas. Tudo para revelar-se como representante ideal da empresa (Laclau, 1996), inclusive, passando a incorporar um personagem "orientador" na elaboração de projetos a serem financiados por ela.

Observa-se, segundo dados dos documentos da Empresa 01, que, a partir da avaliação quanto à possibilidade da ampliação dos conflitos, realizada pelo "RE01", a empresa passou a destinar maior quantidade de recursos para investimentos na comunidade. As denúncias dos assentados junto ao MPF, que tratavam de problemas nas casas (rachaduras), da poluição sonora (buzina do trem), dentre outras, e as solicitações de esclarecimentos vindas desse órgão influenciam para que a empresa ampliasse sua articulação de estratégias para a antecipação de conflitos. Isso possibilitou que o representante realizasse reuniões para que a comunidade selecionasse os investimentos a serem recebidos.

Com o início dos investimentos e suas respectivas obras, que podem ser enquadradas como reproduções simbólicas (Bourdieu, 1989), a empresa passou a utilizá-las como exemplos de que se dispõe a dialogar e a beneficiar as comunidades, estabelecendo-se um momento de relação harmoniosa entre os dois agentes (Assentamento e RE01). Nesse processo, tem-se a instalação de uma luta simbólica (Bourdieu, 2001), com o uso de ideias-força (Bourdieu, 1989) que visam a disseminar uma simbologia positiva da empresa. De um lado, ainda existem os comunitários contrários aos investimentos; de outro, a empresa que utiliza os investimentos como referenciais simbólicos de ação positiva.

No caso da Empresa 02, em termos de início da relação com a Comunidade 02, houve a solicitação do Ministério Público Federal (MPF) para que o território da Reserva Extrativista (RESEX) fosse incluído no cronograma das reuniões de divulgação dos novos investimentos. A equipe da silvicultora avaliava que a RESEX não se enquadrava como AII (Área de Influência Indireta).

Como não houve mudanças na equipe de atuação junto à comunidade da RESEX, o Representante da Empresa 02 - RE02 - foi o responsável pelo início da relação, e ainda continua nessa posição. Diferentemente do outro caso estudado (Empresa 02), aqui todos são funcionários ligados diretamente à empresa, e fazem parte da equipe designada para o relacionamento com comunidades, sendo importante informar que as análises se pautam na atuação do RE02.

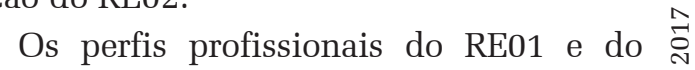
RE02 são muito diferenciados. O segundo é graduado, com licenciatura; já trabalhou em diversos órgãos públicos municipais, estaduais e federais e consta, no seu histórico, uma forte atuação partidária, ligação com políticos e atuação nos movimentos sociais da região onde trabalha. Em termos de hierarquia profissional, o RE02 está no topo da equipe de atuação em comunidades e existem profissionais que são responsáveis por áreas específicas, mas todos os eventos e investimentos relacionados a esse campo são planejados e orientados por ele.

Como destaca Zucker (1987), as empresas buscam implantar novos mecanismos para ampliar os resultados positivos com as partes 
interessadas, ainda que externas ao cotidiano empresarial. E, nesse sentido, o RE02 passou a disseminar, no seio da comunidade, que investimentos financeiros seriam feitos e que ele se empenharia nessa concretização. Assim, os extrativistas passaram a relacionar a imagem positiva do RE02 à empresa, pois ele se apresentava como representante com poder de influência. Observe-se que ele não tinha experiência na área privada, pois sempre foi ligado a órgãos públicos, também ligados diretamente à comunidade da RESEX. A Empresa 02 considerou esse histórico para selecioná-lo, pautando-se, assim, em um novo rito: contratar pessoas com trabalho reconhecido em comunidades.

Por seu caráter de liderança em movimentos políticos e sociais, ele foi cogitado para o cargo que atualmente ocupa, a fim de acompanhar o processo de licenciamento ambiental, além de ser uma figura positiva no seio das comunidades rurais, como é constantemente mencionado nas entrevistas com os comunitários, conseguindo reduzir significativamente manifestações contrárias à empresa, principalmente, na zona rural. Tem-se, assim, a aplicação do que Bourdieu (1989) menciona como uma autorização de representação com foco nos que receberão o poder simbólico. Em relação ao caso da RESEX, havia um grande movimento contrário à implantação స్ dos investimentos da Empresa 02, e algumas lideranças e os movimentos sociais ligados aos extrativistas disseminavam avaliações extremamente negativas das obras. Com o início da divulgação direta da empresa nas comunidades, o RE02 foi fundamental na capitalização simbólica positiva para a silvicultora, pois reA.
Considerando as entrevistas e as análises em campo, a seleção de ambos os representantes para atuação nas relações com as comunidades segue o que Fleury (1987) destaca como uma "ritualização dos heróis". E como principais estratégias destacam-se os processos de "inculcação" e de "trabalho pedagógico” (Bourdieu, 2011; Rosa; Brito, 2009), além dos mecanismos de renovação e reforço (Trice; Beyer, 1984), para propiciar maiores ganhos nos seios das comunidades. Destaca-se que o investimento financeiro é utilizado nas duas relações como estratégia de dissipação de possíveis conflitos, tanto na RESEX como no assentamento, pois esse é o maior problema dessas comunidades. Tais investimentos recebem o peso da representação do poder da empresa (Enriquez, 1992; Silva, 2000) e, com o apoio do órgão estatal responsável pela área, esses representantes também exercem uma influência como "orientadores" de projetos que são viáveis para investimentos.

Os processos de comunicação (Almeida; Nunes, 2007) e de manifestações públicas de representação (Bourdieu, 1991b) têm sido de grande importância para a ampliação do poder simbólico das empresas. Os dois representantes citados têm desempenhado importante papel de interlocução (Andrade, 2010), pois, além de conseguirem a pacificação nas relações, têm disseminado a simbologia de representante ideal (Hofstede, 1991), tanto no seio da organização, quanto para os comunitários e suas redes de relação. Entretanto, com um histórico ligado aos movimentos sociais, o representante da silvicultora se torna obrigado a beneficiar a empresa, mesmo que se apresente como "benfeitor" da comunidade. Ao mudar sua "classe" de atuação social, tem-se o que Nunes (2013) enfatiza como mudança de habitus (Bourdieu, 2011); com isso, mudando-se a trajetória, mudam-se as disposições pessoais, individuais (Crossley, 2001).

Por outro lado, o poder de negociação cedido aos representantes amplia sua capacidade de ação, enfatizando-se que a principal 
diferença nos resultados se encontra exatamente na simbologia de confiança que o RE02 representa para a comunidade da RESEX, e nos sinais de incorporação (Bourdieu, 1991d) que ele agrega à representada. Isso ocorre quando: a) sabendo de sua boa avaliação junto à comunidade, agrega essa simbologia à empresa, sempre mencionando que pode apoiar investimentos adequados para a comunidade; b) ao serem realizados os primeiros investimentos financeiros, o RE02 demonstra a possibilidade de ganhos econômicos comunitários, mas vincula esse resultado à necessidade de manutenção da "parceria", ou seja, de uma relação sem conflitos.

Deve-se destacar que, mesmo com todo o investimento financeiro e com uma mudança no capital simbólico das empresas, tornando-o mais positivo, os representantes ainda enfrentam agentes que discordam da ação das empresas, nos territórios das comunidades. Mas, nos dois casos, os comunitários que avaliam negativamente os investimentos empresariais passam a ser classificados como contrários ao desenvolvimento econômico dos assentados e dos extrativistas. Se, antes dos investimentos privados, as comunidades viviam um certo consenso, apesar de haver três associações no assentamento, agora há uma extrema divisão entre os componentes, e, nos dois casos, os representantes empresariais buscam estabelecer uma relação de confiança (Barney; Hansen, 1994), interorganizacional, com um indicativo de que nenhum dos agentes utilizará meios para se sobressair sobre o outro. Mas a busca por uma posição de dominação em um campo é realidade em qualquer contexto de organizações (Bourdieu, 2005), buscando-se ampliar um poder, quando se trata das investidas de grandes empresas e seus lucros.

A Empresa 01 iniciou seu trabalho de relacionamento com a comunidade com o intuito de realizar diagnósticos sobre a contextualização sociopolítica, que, como destaca Aktouf (1993), é atividade comum no meio empresarial. Esse processo foi iniciado consi- derando-se que os investimentos suas atividades poderiam causar danos ao cotidiano do assentamento. As ações do RE01 tiveram grande relevância, pois, além de se tratar de um funcionário direto da empresa, que contava com maior apoio dela, era dotado de maior habilidade para dirimir os conflitos. Ele também se apresentou como um representante realmente engajado (Bourdieu, 2011; Hobbes, 2002) com seus representados.

Apesar da experiência na área da empresa onde atua, o RE01 se encontra na base de uma estrutura complexa, onde qualquer tipo de decisão deve seguir trâmites burocráticos internos, em que as demandas devem passar por várias instâncias até que seja tomada uma decisão. Essa diferença no poder de decisão tem sido um dos principais diferenciais na resolução dos conflitos, como buscamos demonstrar.

\section{CONSIDERAÇÕES FINAIS}

Este artigo analisou as estratégias adotadas pelas empresas na seleção de seus representantes, ou "porta-vozes autorizados", mostrando que, ao atuarem junto às comunidades, eles podem interferir diretamente nos resultados. As grandes empresas desenvolvem a capacidade de interferir diretamente na sua avaliação a partir do momento em que selecionam representantes cujas vivências sejam relacionadas com causas defendidas por seus antagonistas, nesse caso, os movimentos sociais do meio rural. Isso é complementado com a transformação dos investimentos financeiros em referenciais positivos de atuação nas comunidades.

Os resultados demonstram que as estratégias adotadas pela Empresa 02 e por seu representante implicaram a ampliação do que seria uma representação positiva, pois têm conseguido agregar capital simbólico proveniente do representante contratado para esse fim. Além disso, o fato de facilitar o acesso do representante aos recursos da empresa, mesmo 
que estrategicamente, tem possibilitado exponenciar esses resultados. Nesse caso, considera-se o fator de brevidade e de demonstração de capacidade de resolução das demandas dos comunitários e, no caso da Empresa 01, o destaque se deve ao fato de que seu representante consegue aplicar estratégias de inculcação, já que as obras realizadas pela empresa tornam-se instrumentos de inclusão de uma nova representação da ação empresarial, nesse caso favorecendo a mineradora.

Torna-se importante destacar que os processos metodológicos adotados nesta pesquisa podem ser aplicados em mais campos de relação entre empresas e comunidades, principalmente rurais, para que elas percebam que têm participado de relações estratégicas e que os benefícios imediatos podem se transformar em perdas. Tais perdas estão relacionadas com processos de desterritorialização (Paludo, 2015; Stolerman et al., 2015; Zhouri; Oliveira, 2005) e de desagregação das suas redes de relações historicamente estabelecidas. É preciso que mais pesquisas como esta sejam realizadas e que seus resultados sejam instrumentos de ampliação do capital cultural das comunidades.

Recebido para publicação em 19 de abril de 2016

\section{REFERÊNCIAS}

AKTOUF, O. O simbolismo e a cultura de empresa: dos bu abusos conceituais às lições empíricas. In: CHANLAT, J. F. (Org.). O indivíduo na organização: dimensões esquecidas. $\therefore$ São Paulo: Atlas, 1993. v. 2, p. 39-79.

尺 ALMEIDA, A. L. C.; NUNES, D. A. Mensagens corporativas ¿ e a construção de sentido sobre as organizações. Revista Brasileira de Comunicação organizacional e de Relações §े públicas, São Paulo, n. 7, p. 259-179, jul./dez. 2007.

ALMEIDA, K. M. P. Distinção e transcendência: a estética sócio-lógica de Pierre Bordieu. Mana, v. 3, n. 1, p. 155-168, 1997.

ANDRADE, Z. A. F. Gestão da ética nas organizações: i possibilidades aos profissionais de relações públicas e comunicação organizacional. 2010. 236 f. Tese (Doutorado em Comunicacão) - Escola de Comunicacõos e Artes, Universidade de São Paulo, São Paulo, 2010.

BARNEY, J.; HANSEN, M. H. Trustworthiness as a sourceofcompetitiveadvantage. Strategic management journal, v. 15, p. 175-190, 1994.

BONI, V.; QUARESMA, S. J. Aprendendo a entrevistar: como fazer entrevistas em Ciências Sociais. Em tese, v. 2, n. 1, p. 68-80, 2005.

BOURDIEU, P. O poder simbólico. Tradução de Fernando Tomaz. Rio de Janeiro: Bertand Brasil, 1989.

Identityandrepresentation: elements for a criticalreflectionsontheideaof region. In: John B. Thompson. Translated by Gino Raymond and Matthew Adamson. Cambridge: Polity press, 1991a. p. 92106.

Description and prescription: the conditionsof possibility and the limits of political effectiveness. In: Language and symbolic power. Edited and introduced by John B. Thompson. Translated by Gino Raymond and Matthew Adamson. Cambridge: Polity press, 1991b. p. 127-136.

Authorized language: the social conditions for the effectivenessof ritual discourse. In: . Languageand symbolic power. Edited and introducedby John B. Thompson. Translated by Gino Raymond and Matthew Adamson. Cambridge: Polity press, 1991c. p. 107-116.

RitesofInstitution. In: Languageand symbolic power. Edited and introducedby John B. Thompson. Translated by Gino Raymond and Matthew Adamson. Cambridge: Polity press, 1991d. p. 117-126.

Meditações pascalianas. Tradução de Sérgio Miceli. Rio de Janeiro: Bertrand Brasil, 2001.

O campo econômico. Tradução de Suzana Cardoso e CécileRaud-Mattedi. Revista Política e sociedade, n. 6, p. 15-57, abr. 2005.

. O campo político. Revista brasileira de Ciência política, n. 5, p. 193-216, 2011.

BUENO, W. C. A personalização dos contatos com a mídia e a construção da imagem das organizações. Revista brasileira de Comunicação organizacional e de Relações públicas, São Paulo, n. 2, p. 11-27, jan./jul. 2005.

BURKLE, E. M. Corporate communityrelations: the principleoftheneighborofchoice. London: Greenwood, 1999.

CAPPELLE, M. C. A.; MELO, M. C. O. L.; BRITO, M. J. Relações de poder segundo Bourdieu e Foucault: uma proposta de articulação teórica para a análise das organizações. Organizações rurais \& agroindustriais, v. 7, n. 3, p. 356-369, 2005.

CASTELLS, M. A Era da informação: o poder da identidade. São Paulo: Paz e Terra, 1999. v. 2.

CROSSLEY, N. The phenomenologicalhabitusand its construction. Theoryand society, v. 30, p. 81-120, 2001.

DUARTE, R. Entrevistas em pesquisas qualitativas. Educar em revista, n. 24, p. 213-225, 2004.

ENRIQUEZ, E. L'entreprisecommelien social: um colosseauxpieds d'argile. In: SAINSAULIEU, R. (Org.). L'entreprise: eu affaire de société. Paris: Presses de la Foundation national de Science politique, 1992. p. 39-58.

FERNANDES, R. B. Pierre Bourdieu e a noção de liderança política. Revista ensaios, v. 2, n. 3, p. 35-38, jan./jun., 2010.

FERREIRA, J. O trabalho político. O social em questão, ano $14, n^{\circ} 25 / 26$, p. 157-186, 2011.

FLEURY, M. T. L. Estórias, mitos, heróis: cultura organizacional e relações do trabalho. Revista de Administração de empresas, v. 27, n. 4, p. 7-18, 1987. 
FRANÇA, F; FREITAS, S. G. Manual da qualidade em projetos de comunicação. São Paulo: Pioneira, 1997.

FREITAS, M. E. Cultura organizacional: sedução \& carisma? 1997. 323f. Tese (Doutorado em Administração) - Escola de Administração de Empresas de São Paulo, Fundação Getulio Vargas, São Paulo, 1997.

GODOY, A. S. Introdução à pesquisa qualitativa e suas possibilidades. Revista de administração de empresas, v. 35 , n. 2, p. 57-63, 1995.

HARDY, C.; CLEGG, S. R. Some darecall it power. In: CLEGG, S. R.; HARDY, C.; NORD, W. R. (Org.). Handbook of organizations studies. London: Sage, 1996.

HOBBES, T. Elementos da lei natural e política. Tradução de Fernando D. Andrade. São Paulo: Ícone, 2002.

HOFSTEDE, G. Culture and organizations. London: McGraw-Hill, 1991.

KLEBA, M. E.; WENDAUSEN, A. Empoderamento: processo de fortalecimento dos sujeitos nos espaços de participação social e democratização política. Saúde e sociedade, v. 18, n. 4, p. 733-743, 2009.

KUNSCH, M. M. K. Planejamento de relações públicas na comunicação integrada. 4. ed. São Paulo: Summus editorial, 2003.

LACLAU, E. Poder e representação. Tradução de Joanildo A. Burity. Estudos sociedade e agricultura, n. 7, p.7-28, dez. 1996

LAYRARGUES, P. P. A cortina de fumaça: o discurso empresarial verde e a ideologia da racionalidade econômica. São Paulo: Annablume, 1998.

MARCHIORI, M. M.; OLIVEIRA, I. L. Perspectives mchallenges, and future directions for organizational communication reserch in Brazil. Management Communication quarterly, v. 22, n. 4, 2009, p. 671-676, mar. 2009

NEVES, J. L. Pesquisa qualitativa: características, usos e possibilidades. Caderno de pesquisas em Administração, São Paulo, v. 1, n. 3, p. 1-5, 1996.

NUNES, N. Desigualdades sociais e ação coletiva nas sociedades contemporâneas: a fecundidade teórica de Pierre Bourdieu e de NicosMouzelis. Sociologia, Porto, v. 25, p. 33-53, 2013. Disponível em: <http://migre.me/ v9d8x>. Acesso em: 21 fev. 2016.
PALUDO, D. F. Barragem no rio Guapiaçu? Conflitos socioambientais e estratégias de resistência. Revista geonorte, v. 4, n. 2, p. 405-419, 2015.

ROSA, A. R.; BRITO, M. J. Ensaio sobre violência simbólica nas organizacões. Revista $O \& S$, Salvador, v. 16, n. 51, p. 629-646, out./dez. 2009.

SELZNICK, P. A liderança na Administração: uma interpretação sociológica. Rio de Janeiro: Fundação Getúlio Vargas, 1972.

SILVA, T. T. A produção social da identidade e da diferença In: . (Org.). Identidade e diferença: a perspectiva dos estudos culturais. Petrópolis: Editora vozes, 2000. p. 73102.

SROUR, R. H. Poder, cultura e ética nas organizações: o desafio das formas de gestão. São Paulo: Campus, 1998

STOLERMAN, P. et al. A implantação da usina hidrelétrica de Jirau no rio Madeira e os processos de desterritorialização em Rondônia. Terr@ plural, v. 8, n. 2, p. 371-387, 2015 .

TENÓRIO, F. G. (Org.). Responsabilidade social empresarial: teoria e prática. 2. ed. Rio de Janeiro: Editora FGV, 2006.

TRICE, H. M.; BEYER, J. M. Studyind organizacional culture sthrough rites and cerimonials. Academyof management reviw, v. 9, n. 4, p. 653-669, 1984.

VIEIRA, A. Cultura, poder e identidade nas organizações. Revista de Administração FEAD, v. 1, n. 1, p. $61-75,2010$.

ZHOURI, A.; OLIVEIRA, R. Paisagens industriais e desterritorialização de populações locais: conflitos socioambientais em projetos hidrelétricos. In: ZHOURI, A.; LASCHEFSKI, K.; PEREIRA, D. B. (Org.). A insustentável leveza da política ambiental: desenvolvimento e conflitos socioambientais. Belo Horizonte: Autêntica, 2005. p. 4964

ZUCKER, L. Instituyional theories of organization. Annual review of Sociology, v. 13, p. 443-464, 1987. 


\section{BUSINESS RITES IN THE RELATION WITH RURAL COMUNITIES IN THE AMAZON REGION OF MARANHÃO}

\author{
Raifran Abidimar de Castro \\ Edna Castro
}

This article presents two forms of action taken by representatives of large corporations with communities in the interior of the Maranhão state, in the Northeastern region of Brazil. We seek to demonstrate, through the concept of business rites, how large companies, in their relationship with rural communities, strategically develop these rites. The methodological procedure adopted is qualitative focused on descriptive and explanatory analysis. Semi-structured interviews with representatives from the communities and the companies were performed, as well as the analysis of official documents of open access and internal documents, which were granted access for this research. As a main contribution, we hold that large companies develop the capacity to interfere directly in the evaluation made by the community. It starts from the moment the companies select the representatives, who have experiences related to causes sustained by their antagonists, in this case, the social movements in the rural area; or when they transform the financial investments into positive references for their action in the communities.

KEYwORDS: authorized spokesperson. Authorized Mots-CLÉs: Porte-parole autorisé. Autorité-autorisé. authority. Representation. Symbolic capital. Représentation. Capital symbolique. Inculcation. Inculcation.

\section{LES RITES DES ENTREPRISES DANS LEUR RELATION AVEC LES COMMUNAUTES RURALES DE L'AMAZONIE DU MARANHAO}

\author{
Raifran Abidimar de Castro \\ Edna Castro
}

Cet article présente deux manières d'agir des représentants des grandes corporations envers les communautés rurales de l'état du Maranhao dans la région nord-est du Brésil. L’objectif est de démontrer, par le biais du concept des rites des entreprises, comment ceux-ci sont implantés de manière stratégique par les grandes entreprises dans leur relation avec les communautés rurales. L'approche méthodologique adoptée est qualitative et met l'accent sur les analyses descriptives et explicatives. Nous avons appliqué des interviews semi-structurées auprès des représentants des communautés et des entreprises et nous avons aussi procédé à l'analyse des documents officiels mis à la dispositiondu public ainsi que de documents internes destinés à notre recherche. Comme contribution principale, nous pouvons affirmer que les entreprises développent une capacité d'interférer directement au niveau de l'évaluation faite par les membres des communautés à partir du moment où elles font la sélection des représentants dont le vécu est en lien avec les causes défendues par leurs antagonistes, dans le cas échéant les mouvements sociaux du monde rural ou encore lorsqu'elles arrivent à transformer les investissements financiers en références positives d'action dans les communautés.

Raifran Abidimar de Castro - Doutorando em Desenvolvimentos Sustentável do Trópico Úmido na UFPA. Mestre em Geografia pela UFPA. Professor de Geografia do Instituto Federal do Maranhão (IFMA). Líder do Grupo de Estudos e Pesquisas "Ambiente, Sociedade e Sustentabilidade - AB'Saber). Publicações recentes: Os reassentamentos involuntários em programas de urbanização e de saneamento: os casos PROMABEN, PROSAMIM e PROBACANGA, revista URBE (Curitiba/PR), 2016; As monoculturas e a sustentabilidade: análises de três regiões do Brasil”, revista Sustentabilidade em Debate (Brasília/DF), 2015.

Edna Castro - Professora Associada IV da UFPA/NAEA; doutorado em Sociologia pela École des Hautes Etudes em Sciences Sociales; pós-doutorado Centre National de la Recherche Scientifique, CNRS, França. Coordenadora do Grupo de Pesquisa sobre Estado, Território, Trabalho e Mercados Globalizados (GETTAM). Av. Perimetral, no 01, bairro Guamá, Belém (PA), CEP 66.075-750. edna.mrcastro@gmail. com. (91) 3201-7231. Publica importantes artigos e capítulos de livros anualmente. Dentre as diversas publicações de reconhecimento, têm destaque: "Dinâmica socioeconômica e desmatamento na Amazônia”, Novos Cadernos NAEA, v. 8, n. 2, p. 5-39, dez. 2005; "Dossiê: Amazônia”, Caderno CRH n 64, Centro de Estudos e Pesquisas em Humanidades, UFBA, 2012. 